\title{
A study on relationship between sports tourism motivation and tourists' re-visiting intention: Based on Logistic model
}

\author{
Zixuan Huang ${ }^{\mathrm{a}}$, Yidan Kong $^{\mathrm{b}}$ and Chunlin Zhou $^{\mathrm{c}}$ \\ School of Geographical Sciences, Nanjing Normal University, NJ 210023, China. \\ aemma_hzx@163.com, b1272530551@qq.com, cclzhou@njnu.edu.cn
}

Keywords: Sports tourism; sports tourism motivation; revisit intention.

\begin{abstract}
The rapid development of sports tourism enriched the new pattern of domestic tourism, and met the increasing diverse needs of modern tourists. It is important to understand the tourism motivations that affect the revisit intention of sports tourists to consolidate the original tourist market and improve the loyalty of tourists. In this paper, firstly, by using the factor analysis method extracted seven sports tourism motivational factors. Then, the relationship between the sports tourism motivation and revisit intention of tourists is measured by the Logistic regression model. The results show that the driving factors of sports tourism motivation have a significant effect on the revisit intention of tourists, but the influence of pull factors on the revisit intention of the tourists is not significant. In the common factors, the motivation of stimulus pursuit, social emotion, escape release, achievement satisfaction and true experience that they are all positive have a significant effect on the revisit intention of the tour. The probability of tourists' revisiting increases with the increase of the five motivational factors, while 'outside propaganda' and 'tourism attractions' has no significant impact on the revisit intention of the travel.
\end{abstract}

\section{Introduction}

Outdoor sports as the main body of the sports tourism have rapid developed, as of November 2016, China's outdoor sports enthusiasts has reached 130 million people [1], indicated sports tourism market contains great potential. However, behind the ascendant of sports tourism, there are prominent problems such as low satisfaction and low revisit of tourists. Particular tourists revisit intention is not only an important index for analyzing and forecasting the revisit rate of tourists but also the key to the sustainable development of sports tourism market. Thus, we should understand what factors will affect the tourists revisit intention. Current research on the influencing factors of revisit intention mainly involves satisfaction [2-4], social background [5], destination image [6-8], perceived value [9], and past travel experience [10,11], but lack of research focus on the psychological factors of tourism before traveling from the perspective of tourism motivation. While, tourism motivation is one of the important areas of tourism research and is considered as the starting point for the study of tourist behavior as well as tourism system [12]. This paper will research the link between sports tourism motivation and tourists revisit intention.

At present, the researches on tourists' intention of revisiting travel mainly focus on mass tourism. Few scholars study the segment of sports tourism, and there is no empirical study on the relationship between sports tourism motivation and revisit intention. In the existing research, Yang demonstrated visitors stay time and mode of transport have a significant impact on the revisit intention [13]. As well as Alegre and Cladera empirical study of tourists visited Balearic Islands found positive relations between four motivations for tourism climatological, beach, environmental and accommodation quality and tourists revisit intention [14]. Mao revealed leisure motivation and learn motivation have a positive relationship with the intention of tourists to revisit [15]. Guo took the Xiamen City as an example for an empirical analysis and found that leisure and cultural tourism motivation has an indirect impact on the revisit intention [4]. Whether sports tourism motivation will have an impact on tourists' revisit intention? Therefore, based on previous research results, this paper measures sports tourism motivation by multi-dimensional method and uses logistic regression model to test its relationship with tourists' revisit intention. 
This study provides some important contributions to the extant literature of sports tourism. First, it changes the existing research focus about sports tourists psychology from as part of sports tourism motivation to as a robust predictor of motivation and revisit intention. Second, by examining sports tourism motivation each dimensions as predictors, our study illustrates push and pull motivation affect tourists revisit intention were different. The push factors have a positive effect on the intention of revisiting but pull factor have no significant effect on it. Third, from practical perspective, this study clearly points out that satisfy tourists motivation and gain good experience had a positive effect on improve tourists revisit rate. Thus, sports tourism operators need to develop targeted marketing strategies to improve the rate of tourists re-visit, sports tourism market share to maintain and add up.

\section{Literature Review}

\subsection{Sports Tourism}

After the sports tourism was proposed in 1966, its definition was concomitant with the maturity of sports tourism theory. Such as Gibson explained sports tourism is a leisure travel activity in which individuals temporarily participate in sports activities, watch sports competitions or visit sport attractions [16]. And Standeven demonstrated sports tourism is an individual's active or passive participation in physical activities outside the residence or office [17], they all emphasized the remoteness of sports tourism participation. In addition, Chen defined sports tourism in both broad and narrow sense, all of which incorporated sports into tourism, as a kind of special tourism, different from general professional sports activities [18]. Along this line of consideration, from the perspective of economics of industrial integration, Yang thought that sports tourism is a new type of service industry that combines the characteristics of sports and tourism [19]. On the whole, the above scholars study the connotation of sports tourism is deepening. In this paper, using Yang definition that sports tourism is the result of cross-integration of sports and tourism industry, emphasizing the complementarity.

\subsection{Tourism Motivation}

Motivation theory is an important theory in psychology that studies how people's choice behavior is activated. It is an important area that can't be ignored in tourism research. Several major theories of motivation in drive theory, arousal theory and expectations of value theory is cited and developed by tourism research. On this basis, Dann put forward the tourism push-pull theory [20], and it was widely accepted and applied by the academic circles. In this way, Goossens proposed hedonic tourism motivation model to further expand push - pull theory [21]. In this paper, the division of motivation dimension of sports tourism is mainly divided into two parts by referring to push-pull theory, including the push factor and the pull factor.

\subsection{Revisit Intention}

Revisit intention is an important topic of concern in tourism research, which has important practical significance to consolidate the original tourist market and increase the revisit rate of tourists. Richard and Larry demonstrated in terms of cost, the development of new customers is to retain the old customers seven times, the customer retention rate increased by $5 \%$, the profit will be a corresponding increase of $25 \%-85 \%$ [22]. In addition, Wang proposed that re-tours make a greater contribution to the tourism market economy than first-time visitors, and managers should study the former as a market segment when formulating marketing strategies [23]. The study of revisit intention began with Gyte et al. [24], and the subsequent studies mainly focused on the influencing factors of tourists' revisit intention.

\section{Methodology}

\subsection{Survey Instrument}

First of all, based on the literature reviews, we set up the interview outline. We have interviewed 6 sports tourists who frequently participate in the sports tourism activities in the outdoor club and 3 professional mountain guides. According to the results of the interview open-coding, in order to determine the initial questions of the questionnaire. The survey questionnaire consisted of the 
following major sections: questions that measured the following constructs-demographic information, sports tourism motivation and tourists' revisit intention. The sports tourism motivation measurement items referenced Cohen's China Localization Scale for measuring tourism motivation [25] and Lu summarized the common phrases used by foreign researchers in recent years to measure tourism motivation [26]. The selected 23 motivation items were rated on a 5-point Likert scale where $1=$ strongly disagree and $5=$ strongly agree. The revisit intention item in the intent to designate whether there is a repeat plan $(1=$ yes, $0=$ no).

\subsection{Data Collection}

The target population was all the sports tourists who visited Peace Mountain Forest Park and Laoshan Resort to recruit prospective respondents, the major sports tourism destination in Nanjing province. Investigators mainly use the participatory observation method to determine their sports tourist identity according to the characteristics of tourists' behavior. During the collection process we tried to observe whether any question in the survey might be confusing the respondents. The survey focus on January to April 2017. A total of 804 tourists agreed to participate in the study, representing an $83.4 \%$ effective rate, among which 675 responses were usable.

\subsection{Analytical Strategy}

First of all, exploratory factor analysis (EFA) was employed to derive the underlying dimensions of sports tourism motivation. Second, using logistic regression analysis to construct recursion exponential model, equation construction form is

$$
\operatorname{Logit}(\mathrm{P})=\alpha+\sum_{i=1}^{n} \beta i X i
$$

Where $\mathrm{p}$ is the probability of occurrence with range $(0,1) ; \alpha$ is the intercept term, which means that when the value of $\mathrm{X}$ is all 0 , the occurrence probability of the dependent variable; $\beta i$ is logistics partial regression coefficient, means when controlling other independent variables, this independent variable causes a change in the natural logarithm of the ratio for each unit change. Logistic equation is usually written as follows by transformation:

$$
1-\mathrm{P}=\frac{1}{1+\exp (\alpha+\beta 1 \mathrm{X} 1+\beta 2 \mathrm{X} 2+\cdots \ldots+\beta \mathrm{nXn})}
$$

In the study, dependent variable is re-visiting intention (choose the measure item "Are you having a heavy travel plan" yes or no), independent variable is the standardization score of each motivation factor of sports tourism (standardized score of each common factor extracted by exploratory factor analysis). The specific form of Logistic regression is as follows:

$$
\text { Recursive probability } \mathrm{R}=\frac{1}{1+e^{-z}}
$$

In the equation, e is natural logarithm; $\mathrm{Z}=\sum_{i=1}^{n} \beta i X i ; \beta i$ is logistics partial regression coefficient; $X i$ is standardized score of each common factor extracted by exploratory factor analysis.

The recursion probability $\mathrm{R}$ is cut at a standard value of 0.5 . If the recursion probability is estimated to be greater than 0.5 , the sports traveler will choose to revisit; if less than 0.5 , he will not choose to revisit [27].

\section{Results}

\subsection{Respondent Profile}

Among the respondents $42 \%$ were male, $58 \%$ were female and $85.8 \%$ between the ages of $20-39$. About $79.1 \%$ of the respondents were held a collage diploma or higher degree. Also, $71.1 \%$ of the respondents frequently participate in sports tourism activities. The percentage of respondents for high income earners was $81.2 \%$. This feature of the sample was considered acceptable because the sample distribution is more uniform and the randomness is ideal.

\subsection{Reliability and Underlying Dimensions of 'Sports Tourism Motivation'}

Principal component analysis (PCA) was used to identify the factor structure of quality of sports tourism motivation and use orthogonal maximum variance method for factor rotation, obtained the rotated factor loading matrix[28]. Results showed that three of the measurement items have a load of less than 0.5 on all factors, in order to ensure the unit-dimensional factors, these three were removed, and the remaining 20 items to be tested again above test. Results showed that the value of Kaiser- 
Meyer-Olkin $(\mathrm{KMO})$ test was 0.899 and Bartlett's Test $(\mathrm{p}=0.000)$, indicated the sample size was largely adequate and means correlations between variables were significantly different from zero. Table 1 shows the outer loadings of measurement items, all items communalities were above 0.6, which indicates satisfactory indicator reliability. PCA generated seven dimensions for sports tourism motivation, named stimulus pursuit, social emotion, escape release, achievement satisfaction, true experience, outside propaganda and tourism attractions. The cumulative variance explained is $64.59 \%$ and Cronbach's Alpha coefficient is 0.871 above the recommended threshold of 0.5 (see Table 1). Classified the extracted seven common factors are into two dimensions of push factor and pull factor. Among them, 'social emotion', 'escape release', 'true experience', 'stimulus pursuit' and 'achievement satisfaction' are the push factors. The intrinsic drive to push the sports tourists participate in tourism activities. And the two motives of 'outside propaganda' and 'tourism attraction' are pulling factors, which are stimulated as external incentives to attract sports tourists to participate in tourism activities.

Table 1 Results of Factor Analysis

\begin{tabular}{|c|c|c|c|c|}
\hline Factors & Items & Loading & $\begin{array}{l}\text { CVE } \\
(\%)\end{array}$ & Cronbach's $\alpha$ \\
\hline $\mathrm{X} 1$ & Let me communicate with more people & 0.747 & 29.739 & 0.677 \\
\hline \multirow[t]{2}{*}{ social emotion } & Enhance my feelings with friends or family & 0.645 & & \\
\hline & Let me make many new friends & 0.767 & & \\
\hline $\mathrm{X} 2$ & Bring fun to my boring life & 0.710 & 38.545 & 0.677 \\
\hline \multirow[t]{2}{*}{ escape release } & Ease the pressure of work or life & 0.725 & & \\
\hline & When involved, can temporarily forget the troubles & 0.729 & & \\
\hline $\mathrm{X} 3$ & Give people a chance to experience in depth & 0.727 & 45.381 & 0.708 \\
\hline \multirow[t]{2}{*}{ true experience } & Different from the traditional form of tourism & 0.722 & & \\
\hline & Get a different travel experience & 0.684 & & \\
\hline \multirow{3}{*}{$\begin{array}{c}\text { X4 } \\
\text { stimulus pursuit }\end{array}$} & Let me adrenaline soaring, very exciting & 0.728 & 50.619 & 0.670 \\
\hline & Challenge yourself, full of unknown & 0.646 & & \\
\hline & Satisfy my curiosity, play personality & 0.686 & & \\
\hline $\mathrm{X} 5$ & Give me satisfaction & 0.632 & 55.618 & 0.688 \\
\hline \multirow[t]{2}{*}{ achievement satisfaction } & Show my experiences to others & 0.745 & & \\
\hline & Let me get a sense of accomplishment & 0.611 & & \\
\hline $\mathrm{X} 6$ & Friends love, affected by their participation & 0.687 & 60.295 & 0.731 \\
\hline \multirow[t]{2}{*}{ outside propaganda } & By ads to attract push & 0.843 & & \\
\hline & Share experiences with other people on the internet & 0.750 & & \\
\hline $\mathrm{X} 7$ & Beautiful scenery or unique humanities drew me & 0.755 & 64.593 & 0.564 \\
\hline Tourism attraction & The freshness of sports attracts me & 0.772 & & \\
\hline Total & KMO:0.899; Bartlett's P-value $=0.000$; & & $64.59 \%$ & 0.871 \\
\hline
\end{tabular}

Note. $\mathrm{CVE}=$ Cumulative variance explained

\subsection{Logistics Regression Analysis}

Prior to regression, the parameters in the regression model should be tested. Table 2 showed the test results of the constant terms in the regression model. The partial regression coefficient (B) value is 2.383 , the standard error (SE) is 0.138 , the degree of freedom (DF) is 1 , and the greater of the Wald value indicated the more importance of the independent variables, the smaller the corresponding significance value. Results showed that the constant term Sig. $=0.000<0.01$ is significant [27].

Table 2 Results of Step 0

\begin{tabular}{ccccccc}
\hline & B & S.E. & Wald & DF & Sig. & Exp(B) \\
\hline Setp0 constant & 2.383 & 0.138 & 296.461 & 1 & 0.000 & 10.842 \\
\hline
\end{tabular}

Therefore, for the research formula (3), the factors are set as: X1 = social emotion; X2 = escape release; $\mathrm{X} 3=$ true experience; $\mathrm{X} 4=$ stimulation pursuit; $\mathrm{X} 5=$ achievement satisfaction; $\mathrm{X} 6=$ outside propaganda; $\mathrm{X} 7=$ tourism attraction. Wald's forward-step-by-step selection of independent variables, $\mathrm{X} 5=$ achievement satisfaction, $\mathrm{X} 4=$ stimulation pursuit, $\mathrm{X} 2=$ escape release, $\mathrm{X} 1=$ social emotion and $\mathrm{X} 3$ = true experience gradually selected in model; $\mathrm{X} 6=$ outside publicity and $\mathrm{X} 7=$ tourism attraction did not enter the model. Results showed the coefficient value, Standard error, degree of freedom, Wald value and significant level (see table 3, 4). 
Table 3 Variables have access to the Logistic Regression Equation

\begin{tabular}{ccccccc}
\hline Variables & B & S.E. & Wald & DF & Sig. & Exp(B) \\
\hline X1 & 0.391 & 0.147 & 7.046 & 1 & $0.008^{* * *}$ & 1.478 \\
X2 & 0.362 & 0.126 & 8.304 & 1 & $0.004^{* * *}$ & 1.436 \\
X3 & 0.314 & 0.130 & 5.875 & 1 & $0.015^{* *}$ & 1.369 \\
X4 & 0.411 & 0.134 & 9.449 & 1 & $0.002^{* * *}$ & 1.509 \\
X5 & 0.353 & 0.121 & 8.500 & 1 & $0.004^{* * *}$ & 1.423 \\
constant & 2.660 & 0.169 & 248.556 & 1 & $0.000^{* * *}$ & 14.299 \\
\hline
\end{tabular}

Note. ${ }^{* * *} \mathrm{p}<0.001 ; * * \mathrm{p}<0.01$

Table 4 Variables have no access to the Logistic Regression Equation

\begin{tabular}{cccc}
\hline Variables & Score & DF & Sig \\
\hline X6 & 2.162 & 1 & 0.141 \\
X7 & 0.169 & 1 & 0.681 \\
Total & 2.314 & 2 & 0.314 \\
\hline
\end{tabular}

When the degree of freedom of each variable is 1 , Wald $=(B / S . E)^{2}$. Logistic regression model of the relationship between sports tourism motivation and revisit intention is as follows:

$$
\text { Logit }(\mathrm{P})=2.660+0.391 \mathrm{X} 1+0.362 \mathrm{X} 2+0.314 \mathrm{X} 3+0.411 \mathrm{X} 4+0.353 \mathrm{X} 5
$$

The partial regression coefficient $\mathrm{B}$ of each sports tourism motivation factor independent variable in the model can be interpreted as: in the case of keeping the other independent variables unchanged or controlling their letting variables, when the sports tourists' social emotion (X1) motivation increase one unit, the natural logarithm of the ratio of tourists choosing 'revisit' to 'non revisit' probability increases by 0.391 units; when 'escape release' one unit is added, the natural logarithm of the ratio of tourists choosing to 'revisit' or 'not revisit' will increase by 0.362 units. Similarly, when the motivation of 'real experience' (X3), 'stimulating pursuit' (X4) motivation and achievement satisfaction (X5) motivation for each additional unit, the natural logarithm of the ratio of tourists choosing 'revisit' to 'non revisit' probability were increased by $0.314,0.411$ and 0.353 respectively. The relationship between each independent variables and the dependent variable strength can be reflected by the partial regression coefficient of the independent variable. The greater the absolute value of the partial regression coefficient $B$ value, the more significant the change of the dependent variable is affected by the independent variable value. The positive and negative of the regression coefficient represent the direction that affects the variation of the dependent variable. However, the correlation between X6 and X7 with revisit intention Sig.> 0.05 is not statistically significant.

The probability that a sport traveler will choose to revisit can be estimated by equation (3), $\mathrm{Z}=2.660+0.391 \mathrm{X} 1+0.362 \mathrm{X} 2+0.314 \mathrm{X} 3+0.411 \mathrm{X} 4+0.353 \mathrm{X} 5$. The five factors that positively affect the intent of revisiting are all assignment 5 (strongly agree), put the value into the revisit-probabilistic model, the tourists revisit probability calculated is $99.2 \%$.

\section{Discussion and Conclusion}

Through empirical research, this paper validates the hypothesis that the tourist motivation has an impact on the tourists' revisit intention at the first time from the perspective of sports tourism motivation. Analyzed the specific components of the tourists intrinsic push motivation and the sports tourism destination pull motivation. The results showed that the sports tourism motivation has a significant impact on the tourists' intention to revisit, and there were obvious differences in the pushpull motivation. The push factors which have a significant positive impact on the intention of revisit. However, the tourism destination pull factors have no significant effect on tourists' revisit. Based on the current analysis, this paper mainly discusses the three tourist motivations of sports tourists in stimulating pursuit, achievement satisfaction and real experience in order to improve the sports tourism revisit rate, to achieve the original cumulative market share, give sports tourism managers useful inspiration. 


\subsection{Explore Sports Tourism Products Stimulate Pursuit Function}

Through the model verification, it is found that there is a strong correlation between the stimulating pursuit motivation of sports tourists and the intention of revisiting. In view of this strong correlation, the sports tour operator can broaden its tourism market by exploring the stimulating pursuit of sports tourism products. In the process of sports tourism, tourists often pursue their unique and exciting experience of tourism products. However, due to the difference of sex, age, occupation, income and educational attainment of sports tourists, there are differences in the demand of sports tourists for stimulating experience. Accordingly, the sports tour operators, in view of the different groups stimulating demand for the sports tourism industry, can provide differentiated products such as skydiving, diving and skiing according to the three types of tourism resources such as altitude, land and water, meet the pursuit of tourists to stimulate the psychological, improve tourist satisfaction and revisit rate.

\subsection{Improve Sports Tourism Products Participation and Experience}

The results showed that there is a strong correlation between achievement motivation and revisit intention of sports tourists. The achievement satisfaction of sports tourists comes from their high participation and strong experience in sports tourism products. The greatest vitality of sports tourism industry lies in its participation and experience, while the active participation of sports tourists is the realization of their physical and psychological emotional experience process. Fluency experience is the best experience in sports, however, to obtain a smooth experience is not only physically pleasing to sport tourists after they participate in sport tourism products, but more importantly, they also reach psychologically the best Experience. There is a strong positive correlation between participation degree and experience effect of sports tourism products. Therefore, sports tourism operators can divide the participatory experience project into three levels of shallow, medium and high levels, according to the order of shallow depth or depth different levels of participation and experience types of sports tourism products.

\subsection{Strengthen the Authenticity of Sports Tourism Products}

Sports tourism industry integration is not only a socio-economic and cultural activities, but also the important content of sports industry commercialization. Accordingly, the sports tour operators in the development of sports tourism products, we must balance the authenticity and commercialization. Sports tourists place more emphasis on depth experience and real experience than traditional mass tourists. Once the commercialization of sports tourism products is too serious, the genuineness and difference will be weakened, making it difficult for sports tourists to return to their true nature in search of the nature, truth-seeking needs are not met, the attractiveness of sports tourism destination will naturally decline. At the same time, the sports tour operators not only need to maintain the authenticity of the products, but also ensure the quality of the sports travel products and eventually achieve the high-quality experience of the sports tourists and the sustainable development of the sports tourism market.

\section{References}

[1]. http://www.spory.gov.cn/n315/n330/c774667/content.

[2]. J.E. Bigné, M.I. Sánchez, J. Sánchez. Tourism image, evaluation variables and after purchase behavior: inter-relationship [J]. Tourism Management, 2001, 22(6):607-616.

[3]. R. Feng, S. Jang. Temporal destination revisit intention: the effects of novelty seeking and satisfaction [J]. Tourism Management, 2007, 28: 580-590.

[4]. A.X. Guo, F.C. Huang. The relationship between tourism motivation, satisfaction, trust and revisit intention [J].Journal of Zhejiang GongShang University, 2013(01): 78-87.

[5]. J.P. Tiefenbacher, F.A. Day, J.A. Walton. Attributes of repeat visitors to small tourist-oriented communities [J].The Social Science Journal, 2000, 37(2):299 -308 
[6]. C. F. Chen, C. Tsaid. How destination image and evaluative factors affect behavioral intentions? [J]. Tourism Management, 2007, 28(4):1115-1122.

[7]. C. Wang, M.K. Hsu. The relationships of destination image, satisfaction, and behavioral intention: an integrated model [J]. Journal of Travel \& Tourism Marketing, 2010, 27(8):829-843.

[8]. A.X. Guo, F.C. Huang, J. Yang. Effects of Destination Image on Perceived Attractiveness and Revisit Intention: A Case Study of Xiamen City [J].Science of tourism, 2015, 29(6):50-67.

[9]. J.F. Petrick, D.D Morais, W.C. Norman. An examination of the determinants of entertainment vacationers' intentionsto revisit [J]. Journal of Travel Research, 2001, 40(1):41-48.

[10]. J. Aleger, M. Cladera. Repeat visitation in mature sun and sand holiday destinations [J]. Journal of Travel Re-search, 2006, 44(3):288-297.

[11]. A. Beerli, J.D. Martín. Factors influencing destination image [J]. Annals of Tourism Research, 2004, 31(3):657-681.

[12]. R.C. Mill, A.M. Morrison. The Tourism System (the 4th Edition) [M]. Dubuque, IA: Kendall /Hunt Publishing Company, 2002. p. 155

[13]. S. Yang, J. Zhang, N.X. Zhao. A Study on Tourists' Traveling Experience in Tourist destinations and revisit intention_—A case Study of Yixing [J]. Tourism Tribune, 2008(5): 4248 .

[14]. J. Alegre, M. Cladera. Analysing the effect of satisfaction and previous visits on tourist intentions to return [J]. European Journal of Marketing, 2009, 43(5/6):670-685.

[15]. X.G. Mao, J.P. Song. A Study on relationship between tourist's motivation and re-visitation intention: Based on Logistic model [J]. Human Geographic, 2011(6):149-154.

[16]. H. J. Gibson. Active sport tourism: who participates? [J]. Leisure Studies, 1998, 17(2):155170.

[17]. J. Standeven, P.D. Knop. Sport tourism [M]. 1998.

[18]. T.X. Chen, Z.P. Xie. Study on function of market exploitation of sports tourism [J]. Journal of Sports and Science, 2012(2):88-90.

[19]. Q. Yang. Driving force and path mechanisms of the converged development of the sports tourism industry [J]. Journal of Physical Education, 2016(4):55-62.

[20]. G.M.S. Dann. Anomie, ego-enhancement and tourism [J]. Annals of Tourism Research, 1977, 4(4):184-194.

[21]. C. Goossens. Tourism information and pleasure motivation [J]. Annals of Tourism Research, 2000, 27(2):301-321.

[22]. R.A. Heiens, L.P. Pleshko. Categories of customer loyalty: an application of the customer loyalty classification framework in the fast food hamburger market. [J]. Journal of Food Products Marketing, 1996, 3(1):1-10.

[23]. D.G. Wang Tourist behavior and repeat visitation to Hong Kong [J]. Tourism Geographies, 2004, 6(1):99-118.

[24]. D.M. Gyte, A. Phelps. Patterns of destination repeat business: British tourists in Mallorca, Spain [J]. Journal of Travel Research, 1989, 28(1):24-28.

[25]. E. Cohen. Nomads from Affluence: Notes on the Phenomenon of Drifter-Tourism1 [J]. International Journal of Comparative Sociology, 1973, 14(1):89-103. 
[26]. H.M. Zhang, L. LU. Summary on study of tourist Motivation abroad in the recent ten years [J]. Areal research and development, 2005(2):60-69.

[27]. S. Menard. Applied logistic regression analysis. Thousand Oaks, CA: Sage, 1995[J]. 2010.

[28]. J.R. Hair, R. Anderson, Tatham, et al. Multivariate Data Analysis with Reading [J]. 1995, 151. 